\title{
IDIOPATHIC INFLAMMATORY PSEUDOTUMOR OF THE CAROTID SHEATH
}

\author{
Luciano Farage", Ana Carolina B.S. da Motta', \\ David Goldenberg', Nafi Aygun', David M. Yousem'
}

\begin{abstract}
We present a biopsy proven case of 47 years-old man with a carotid pseudotumor, clinically presented as carotidynia. CT showed a mass encasing and narrowing the common carotid artery and MRI showed hypointense signal in $\mathrm{T}_{2}$ and intense enhancement after contrast media administration. The patient was suspected to have an inflammatory process and steroids were prescribed. Eight days after the steroid treatment significant radiological and clinical improvement was observed. The patient remains free of symptoms.
\end{abstract}

KEY WORDS: carotid mass, inflammatory pseudotumor, carotidynia.

\begin{abstract}
Pseudotumor inflamatório idiopático da bainha carotídea
RESUMO - Apresentamos um caso comprovado por biópsia de pseudotumor carotídeo em um homem de 47 anos, com apresentação clínica de carotidinia. A TC mostrou massa envolvendo e estenosando a artéria carótida comum direita e a RM apresentava lesão com hipossinal em T2 e importante realce com o uso de meio de contraste paramagnético. O paciente recebeu a hipótese de lesão inflamatória e um tratamento com corticosteróides foi iniciado. Após oito dias de tratamento uma melhora clínica e radiológica significativas foram observadas. $O$ paciente permanece assintomático.
\end{abstract}

PALAVRAS-CHAVE: massa carotídea, pseudotumor inflamatório, carotidinia.

Unilateral painful neck mass has a wide range of differential diagnosis that includes lymphadenitis, salivary gland diseases, metastasis from mucosal carcinomas and musculoskeletal etiologies'. Some of the carotid artery and carotid sheath diseases must be included in the different diagnosis such as carotidynia $^{2,3}$, inflammatory pseudotumor ${ }^{4-7}$, carotid body paraganglioma ${ }^{8,9}$, aneurysm, giant cell arteritis, arterial dissection and arterial rupture with hematoma formation ${ }^{10}$.

We present a case of a painful presentation of a non-specific inflammatory mass that encases and narrows the common carotid artery, mimicking a neoplastic process.

\section{CASE}

A 47-year-old white man presented with a 3-month history of a painful mass in the lateral aspect of the right side of the neck. The pain was progressive, and associated with swallowing difficulty and headache. There was no history of fever, weight loss, nocturnal sweating, drug allergies or use of ergot derivates or methysergide. His past medical history included hypothyroidism and chronic obstructive sleep apnea treated with a continuing positive airway pressure unit (CPAP).

On physical examination a tender mass was palpated in the right side of the neck. There was no palpable adenopathy. The cranial nerves, oropharynx and larynx were unremarkable.

A contrast-enhanced neck computed tomography (CT) performed three months earlier at an outside hospital showed a circumferential non-enhancing mass around the right common carotid artery. A magnetic resonance imaging (MRI) was also performed at an outside facility two months earlier and showed interval enlargement of the mass which was hypointense on $\mathrm{T}_{2} \mathrm{~W}$ images (Fig ${ }_{1} \mathrm{~A}$ ) and demonstrated prominent and homogenous enhancement with Gadolinium-based contrast material (Fig $1 B$ and ${ }_{1} C$ ).

The patient was referred to our institution with a possible diagnosis of carotid body paraganglioma. A follow-up neck CT showed the same findings of previous exams (Fig $2 A)$. A possibility of an inflammatory lesion was raised and the patient was started on steroid and antibiotic treatment. Follow the initial diagnosis of vascular mass, eight days af-

'MD, The Russell H. Morgan Department of Radiology and Radiological Science, The Johns Hopkins Hospital, Baltimore, MD, USA; ${ }^{2} \mathrm{MD}$, Department of Otolaryngology and Head and Neck Surgery, The Johns Hopkins Hospital, Baltimore, MD, USA.

Received 16 July 2007. Accepted 25 September 2007.

Dr. Luciano Farage - SQS 207 Bloco A apto 201 - 70253-010 Brasilia DF - Brasil. E-mail: lucianofarage@ig.com.br 

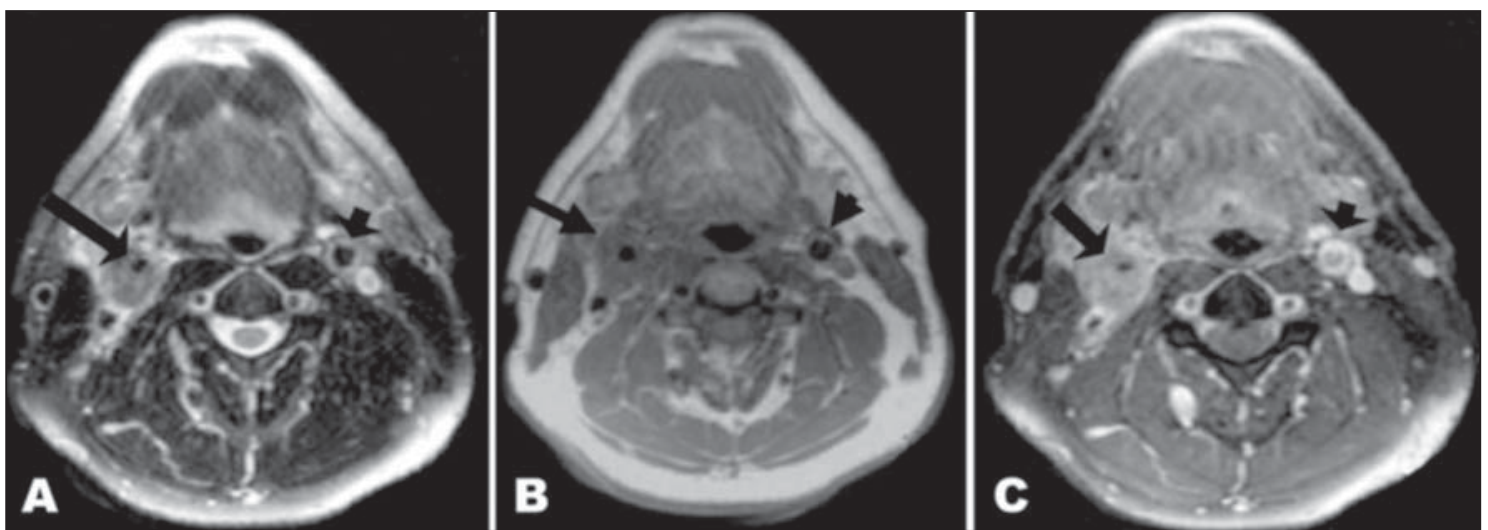

Fig 1. Axial T2 weighted (TR $4000 \mathrm{~ms} / \mathrm{TE} 85 \mathrm{~ms}$ ) (A) and T1 weighted (TR $800 \mathrm{~ms} / 30 \mathrm{~ms}$ ) pre (B) and post contrast with fat suppression (C) scans show a $4.0 \mathrm{~cm}$, low signal intensity, mass encasing the CCA (long arrow) and an intense enhancement of the mass with no differentiation between mass and vessel wall (arrow).
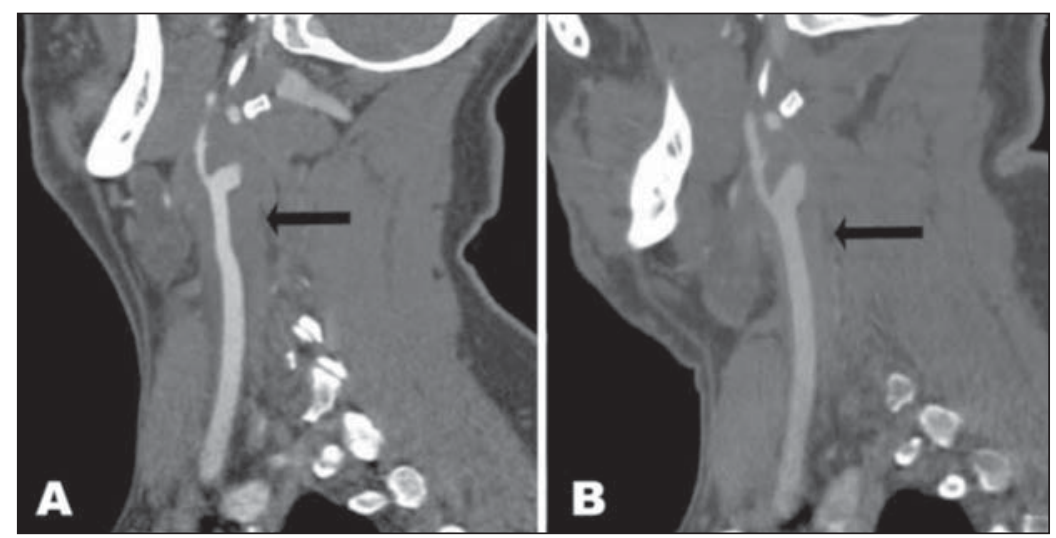

Fig 2. A) The Contrast enhanced CT scan with sagittal reconstruction shows a $4.0 \mathrm{~cm}$ mass encasing the common carotid artery (arrow). B) Eight days after the steroid treatment, the mass is smaller with no apparent narrowing of the CCA (arrow).

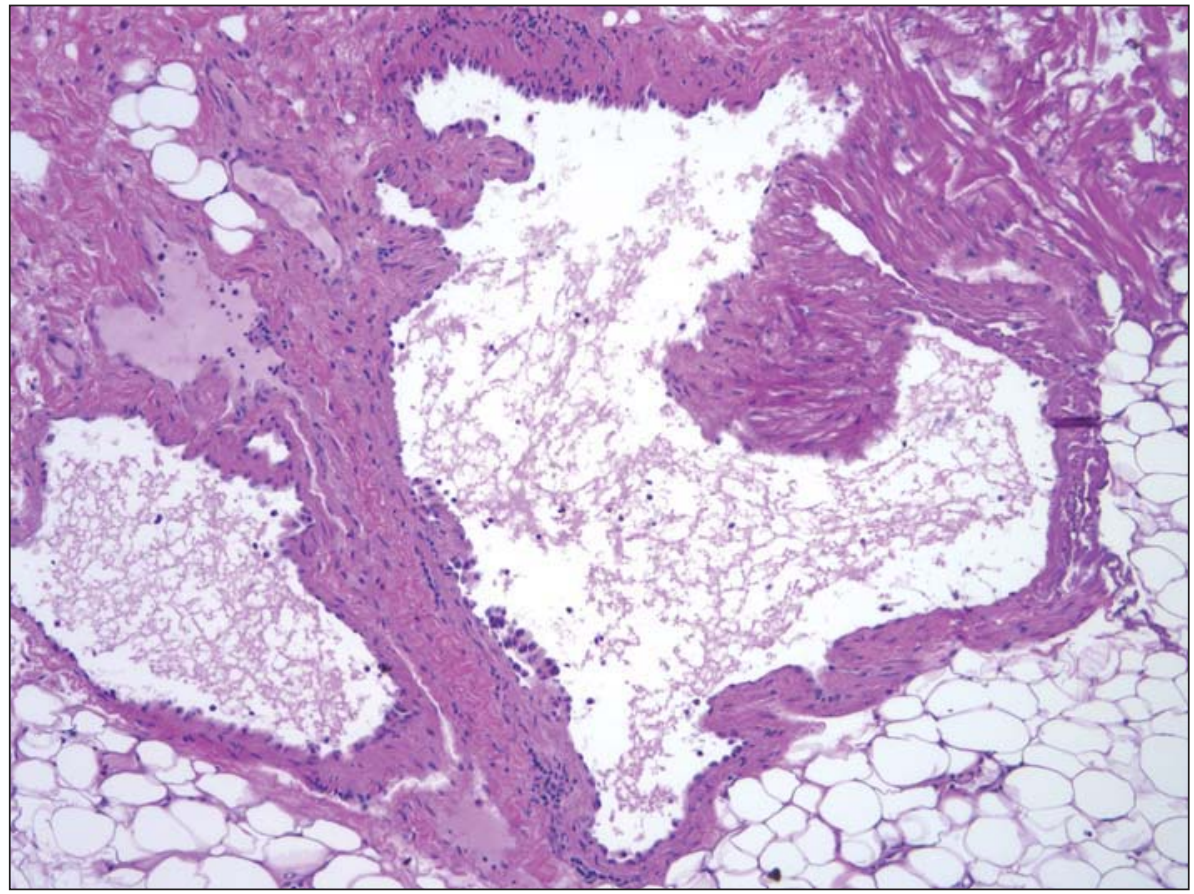

Fig 3. A medium power photomicrograph (Hematoxylin-Eosin stain X100) shows fibro-adipose tissue with numerous dilated vascular spaces. 
ter the beginning of the medical treatment was started, an angiographic study was performed for embolization planning and it was unremarkable. At the same day a new CT was performed and showed a significant reduction in the size of the mass with resolution of the previously noted vascular narrowing (Fig 2B). The patient underwent an open surgical biopsy, at the same day, for definitive diagnosis. An ill-defined tissue within the carotid sheath was found and it was adherent to the carotid artery. The biopsy specimen showed non-specific chronic inflammation, and no evidence of a neoplasm or specific finding of any etiology (Fig 3). No granulomas were seen. There was no evidence of an active infection. The pathologic findings did not support vasculitis.

The patient was discharged and prescribed oral prednisone and amoxicillin/clavulanate potassium.

An extensive work-up for collagen-vascular, infectious and granulomatous diseases did not point to a specific etiology. Antinuclear antibody (ANA), Lyme titer and vasculitis work-up were negative. A complete dental evaluation (clinical and panoramic X-ray film) was performed and nothing remarkable was found. The patient currently remains free of symptoms and no recurrence on imaging was seen 12 months after the surgery.

\section{DISCUSSION}

Inflammatory pseudotumor presents as a mass lesion in various anatomic sites including the central nervous system, orbit, head and neck, lungs, retroperitoneum and pelvis. It is of unknown etiology but in some cases there is an association with the use of ergot derivates and methysergide ${ }^{4-7}$. Pseudotumor of the carotid space is very rare ${ }^{5-7}$. Coffin et al. did not find a single case of carotid space involvement in their review of 84 cases of pseudotumor 4 .

Radiographic presentation includes a mass encasing the carotid bifurcation. On MRI the mass is usually isointense to the skeletal muscle on $\mathrm{T}_{1}$ and $\mathrm{T}_{2}$ weighted images and demonstrate prominent enhancement after contrast media. Angiography shows no vascularity $^{7}$. Occasionally, vessel narrowing can be seen ${ }^{5-7}$.

Carotidynia is a unilateral clinical pain syndrome described as neck pain aggravated by movement such as swallowing or chewing ${ }^{1-3,11}$. The clinical criteria described by the International Headache Society (IHS) Classification Committee ${ }^{12}$ consist of: A) At least one of the following overlying the carotid artery: 1- Tenderness; 2- Swelling; 3- Increased pulsations. B) Appropriate investigations not revealing structural abnormality; C) Pain over the affected side of the neck; may project to the ipsilateral side of the head. D) A self-limited syndrome of less than 2 weeks duration. On cross sectional imaging, some authors reported a smooth rim of enhancement after intravenous injec- tion of gadolinium on T1 weighted MR images of the carotid wall as a marker of carotidynia.

Our patient had a mass within the carotid sheath with encasement of the CCA.

The low T2 signal may be an important clue for differential diagnosis because inflammatory processes and tumors usually present a high T2 signal because of the increased water content. Pseudotumor has a fribrotic component that accounts for relatively low T2-signal| ${ }^{4,7-9}$.

Histopathologically pseudotumor is represented by fibrotic tissue (spindle cells) with infiltration by lymphocytes and plasmacytes. No granulomatous, giant cell or necrotic changes are seen ${ }^{4-7}$. In our case the open biopsy was performed after eight days of steroids and antibiotics treatment and it could change the histological characteristics of the mass.

The treatment of pseudotumor includes use of steroids, but a definitive diagnosis often requires surgery. This is a benign process but it occasionally recurs $^{5-7}$.

Hematoma from a dissection or contained rupture must be considered in the differential diagnosis given that neck pain was main reason for clinical presentation. Imaging can show a thickened wall with or without enhancement ${ }^{10}$. A bright T1-signal is usually seen at the vessel wall up to several months after the dissection occurs.

Carotid body tumor and glomus jugulare tumor are the most common paragangliomas of the head and neck ${ }^{8}$. Carotid body tumor has a good prognosis with no recurrence when totally removed ${ }^{8,9}$. No sex predilection is observed and it occurs most commonly between the fifth and sixth decades of life $e^{8,9,13,14}$. The radiological findings include a mass that encases or splays the carotid vessels and presents as low density on CT and decreased signal on $\mathrm{T} 1$ and increased signal on T2 weighted MRI. It has a great avidity for contrast media. A "salt and pepper" appearance may be seen on MRI due to "flow-void" of the vessels within the tumor ${ }^{8}$. Typically, there is no stricture of the vessels. The treatment includes surgery with or without a preoperative embolization to reduce the size of the tumor and blood loss during surgery 8,9,14,15.

In our case the mass reduced in size within a week of steroid treatment. This changed the surgical plan from resection of the mass and carotid reconstruction to an open biopsy. The course of this case shows the importance of reevaluation of some lesions after the initial diagnosis and medical therapy. The low T2 
signal intensity associated with pseudo-inflammatory lesions can help differentiating these lesions from paragangliomas and schwannomas.

\section{REFERENCES}

1. Burton BS, Syms MJ, Petermann GW, Burgess LP. MR imaging of patients with carotidynia. Am J Neuroradiol 2000; 21:766-769.

2. Syms MJ, Burton BS, Burgess LP. Magnetic resonance imaging in carotidynia. Otolaryngol Head Neck Surg 1997;117(Suppl):S156-S159.

3. Buetow MP, Delano MC. Carotidynia. Am J Roentgenol 2001;177:947.

4. Coffin CM, Watterson J, Priest JR, Dehner LP. Extrapulmonary inflammatory myofibroblastic tumor (inflammatory pseudotumor): a clinicopathologic and immunohistochemical study of 84 cases. Am J Surg Pathol 1995; 19:859-872.

5. Okamoto M, Takahashi H, Yamanaka J, Nemoto S, Kuno K, Ishii T. Sclerosing inflammatory pseudotumor arising from the carotid artery region. Auris Nasus Larynx 1997;24:315-320.

6. Kim GE, Cho YP, Chung DH, Kwon TW, Kim OJ. Inflammatory pseudotumor of carotid artery: a case report. Cardiovasc Surg 1999;7:342-347.

7. Lee HK, Kim EJ, Ro JY, Kwon Y, Kim GE. Inflammatory pseudotumor of the carotid artery: radiologic findings. J Comput Assist Tomogr 2003; 27:253-256.

8. Rao AB, Koeller KK, Adair CF. From the archives of the AFIP: paragangliomas of the head and neck: radiologic-pathologic correlation. Armed Forces Institute of Pathology. Radiographics 1999;19:1605-1632.

9. Luna-Ortiz K, Rascon-Ortiz M, Villavicencio-Valencia V, Granados-Garcia M, Herrera-Gomez A. Carotid body tumors: review of a 20-year experience. Oral Oncol 2005;41:56-61.

10. Kim KH, Sung MW, Oh SH. Spontaneous rupture of the common carotid artery: a case report. Head Neck 1992;14:496-501.

11. Emmanuelli JL, Gutierrez JR, Chiossone JA, Chiossone E. Carotidynia: a frequently overlooked or misdiagnosed syndrome. Ear Nose Throat J 1998;77:462-469.

12. Headache Classification Committee of the International Headache Society. Classification and diagnostic criteria for headache disorders, cranial neuralgias and facial pain. Cephalalgia 1988;8(Suppl 7):S1-S96.

13. Hill LM, Hastings G. Carotidynia: a pain syndrome. J Farm Pract 1994; 44:71-75.

14. Pellitteri PK, Rinaldo A, Myssiorek D, et al. Paragangliomas of the head and neck. Oral Oncol 2004;40:563-575.

15. Valavanis A. Preoperative embolization of the head and neck: indications, patient selection, goals, and precautions. Am J Neuroradiol 1986; 7:943-952. 